\title{
Gender Differences in Social and Behavioral Determinants of Health in Aging Adults
}

\author{
Elena Byhoff, $M D, M S c^{7}$, Yorghos Tripodis, $P h D^{2}$, Karen M. Freund, $M D, M P H^{7}$, and \\ Arvin Garg, MD, $\mathrm{MPH}^{3}$
}

'Department of Medicine, Tufts Medical Center , Tufts University School of Medicine, Boston, MA, USA; ${ }^{2}$ School of Public Health, Boston University, Boston, MA, USA; ${ }^{3}$ Department of Pediatrics, Boston Medical Center, Boston, MA, USA.

J Gen Intern Med 34(11):2310-2

DOI: $10.1007 / \mathrm{s} 11606-019-05225-\mathrm{x}$

(C) Society of General Internal Medicine 2019

\section{INTRODUCTION}

Adverse social determinants of health $(\mathrm{SDOH})$ are associated with poor health. ${ }^{1}$ Cumulative social risk factors, such as food insecurity and social isolation, have a higher correlation with poor health outcomes than single social risk factors. ${ }^{2}$ New health policy incentives encourage implementation of social and behavioral risk screening and referral models into health care delivery. ${ }^{3}$ Understanding patient variation in facing adverse $\mathrm{SDOH}$ will allow policy makers and health care systems to prioritize screening for those most at risk, and develop targeted SDOH interventions. Women and men may have differing individual and cumulative social risk factors which is relevant when implementing social risk screening. The objective of this research was to examine gender differences in negative $\mathrm{SDOH}$ in adults as they age using nationally representative data. ${ }^{4}$

\section{METHODS}

We used the National Health and Nutrition Examination Survey (NHANES) 2013-2014 survey wave to create a dataset of all non-institutionalized individuals $\geq 18$ years old. NHANES is the only nationally representative dataset with social, behavioral and health outcomes reported at the individual level. Using the National Academy of Medicine's (NAM) ten recommended measures for social and behavioral determinants of health, we created eight variables that aligned with the corresponding domains. ${ }^{5}$ We excluded stress as there was no equivalent variable in the NHANES data, and race/ethnicity as it is not a modifiable risk factor. Each variable was developed using applicable NHANES survey questions, then collapsed and dichotomized based on NAM scoring criteria. ${ }^{5}$ These included the following: (1) low educational attainment, (2) income to poverty ratio (proxy for material hardship), (3) food insecurity, (4) depression, (5) tobacco use, (6) alcohol abuse, (7) low physical activity, and (8) lack of a partner (proxy for social connection). We applied survey weights to

Published online August 5, 2019 estimate nationally representative proportions by gender, which NHANES collects as a self-reported variable, for each risk factor and cumulative risk factors. Chi-square and Student's $t$ tests were used to measure statistically significant gender differences. We evaluated the nationally representative proportion of men and women facing $>3$ cumulative risk factors by age, using 10-year age bands since decades of life are also often used for guideline-driven recommendations for screening (i.e., colon cancer screening at age 50).

\section{RESULTS}

Of the 6113 respondents included in our analysis, 52\% were women (Table 1). Men and women had equivalent mean number of risk factors. Overall, women were significantly more likely to be low income, screen positively for depression, and be unpartnered. Men were significantly more likely to be smokers.

Figure 1 demonstrates the proportions of men and women with the mean number of risk factors or higher for aging adults. Although women and men had similar rates of $>3$ risk factors at younger ages ( $67 \%$ vs $70 \%, p$ value 0.34 ), there was a widening gender gap in risk factors as women and men age. The largest gender difference occurred in the oldest age group, $>70$ years of age; $62 \%$ of women had $>3$ risk factors compared with $50 \%$ of men ( $p$ value 0.002 ).

\section{DISCUSSION}

Our study found that women in the USA face different social and behavioral risk factors compared with men. Women were more likely to live in poverty, screen positive for depression, and be unpartnered. While the youngest men and women had similar number of cumulative social and behavioral risk factors, there was a significantly higher proportion of older women with $>3$ risk factors compared to similarly aged men. These results expand on the existing literature that hypothesizes social risks in older women and men differ because women have a longer life expectancy and outlive their social networks resulting in higher rates of depression and decreasing social connectedness. ${ }^{6}$ Lower lifetime earnings for women also increase their risk of poverty later in life. These are important 


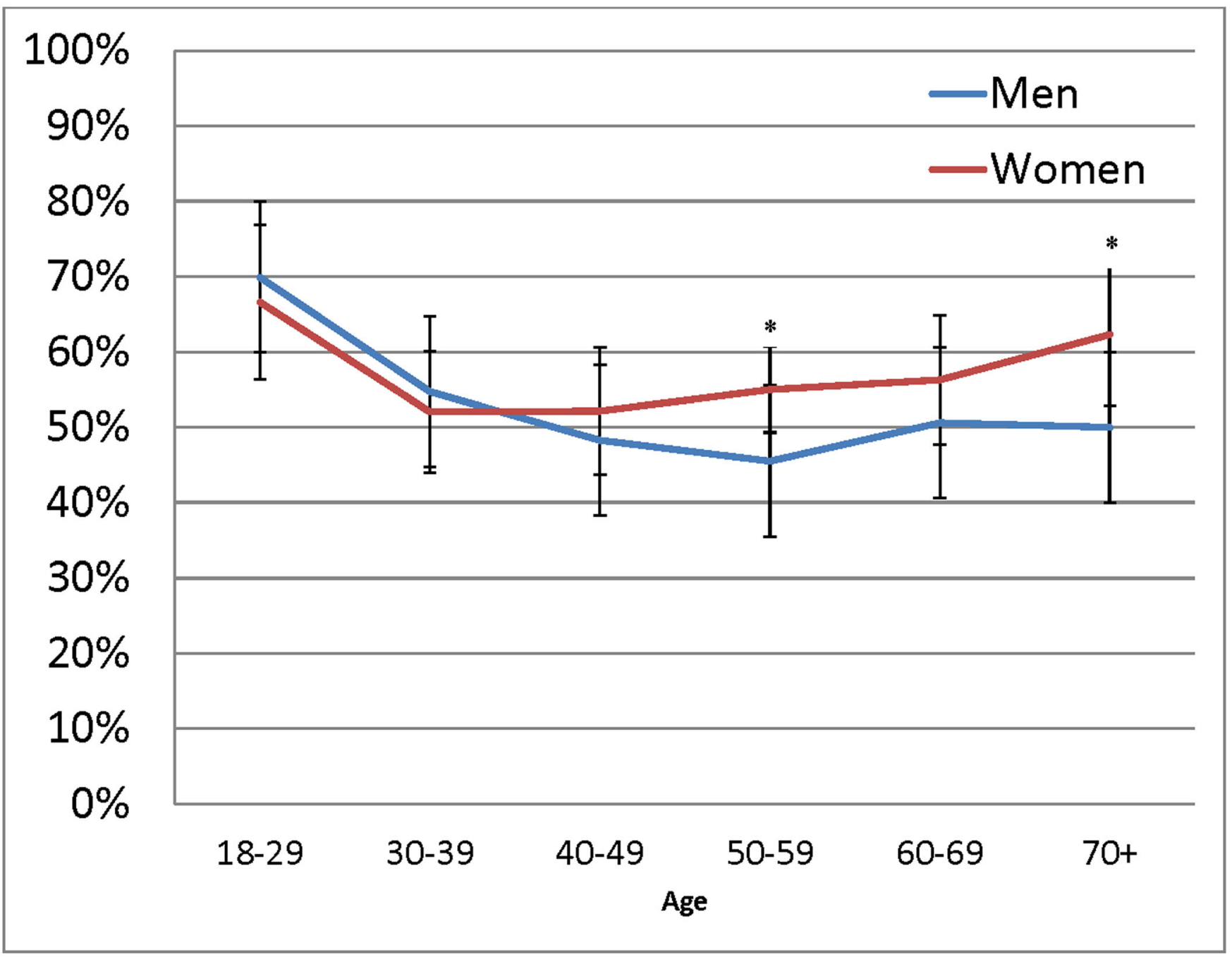

Figure 1 Prevalence of three or more social/behavioral determinants of health by age and gender: NHANES $2013-2014$ survey. * $p$ value $<0.05$.

Table 1 Sample Characteristics-NHANES 2013-2014 Survey Wave

\begin{tabular}{|c|c|c|c|}
\hline & Men & Women & $p$ value \\
\hline$N(\%)$ & $2916(48)$ & $3197(52)$ & \\
\hline Mean age (SD) & $45.8(17.3)$ & 47.1 (17.9) & 0.002 \\
\hline $\begin{array}{l}\text { Social risk factors }(\%) \\
<\text { H.S. diploma } \\
\text { Low income (family income } \leq 200 \% \text { FPL) } \\
\text { Food insecure } \\
\text { Smoker } \\
\text { Not physically active } \\
\text { Unpartnered } \\
\text { Positive depression screen } \\
\text { Positive alcohol screen }\end{array}$ & $\begin{array}{l}686(8) \\
1267(17) \\
832(11) \\
1479(23) \\
1722(27) \\
996(16) \\
513(9) \\
422(13)\end{array}$ & $\begin{array}{l}691(8) \\
1530(21) \\
992(13) \\
1100(20) \\
1887(29) \\
1388(22) \\
857(15) \\
497(16)\end{array}$ & $\begin{array}{l}0.3 \\
<0.001 \\
0.14 \\
0.001 \\
0.24 \\
<0.001 \\
<0.001 \\
0.35\end{array}$ \\
\hline $\begin{array}{l}\text { Cumulative risk factors }(\%) \\
0 \\
1 \\
2 \\
3 \\
4 \\
5 \\
6 \\
7 \\
8 \\
\text { Mean cumulative risk (SD) }\end{array}$ & $\begin{array}{l}126(4) \\
399(14) \\
586(20) \\
628(22) \\
559(19) \\
339(12) \\
205(7) \\
65(2) \\
9(0.3) \\
2.9(1.6)\end{array}$ & $\begin{array}{l}133(4) \\
418(13) \\
661(21) \\
675(21) \\
580(18) \\
433(14) \\
205(6) \\
80(3) \\
12(0.4) \\
3.0(1.7)\end{array}$ & 0.31 \\
\hline
\end{tabular}


considerations as national priorities focus on screening for and addressing SDOH in clinics. A gender-neutral "one size fits all" screening approach may not be appropriate. Tailoring and targeting SDOH screening for women in clinical settings, especially for older women where the prevalence of multiple risk factors is highest, could increase the impact of $\mathrm{SDOH}$ interventions, and subsequently improve women's health and quality of life. Future work should focus on when and how women may be targeted to reduce the accumulation of social risks as they age.

Corresponding Author: Elena Byhoff, MD, MSc; Department of Medicine, Tufts Medical Center Tufts University School of Medicine, Boston, MA, USA (e-mail: ebyhoff@tuftsmedicalcenter.org).

Funding Information The research was financially supported by Eunice Kennedy Shriver National Institute Of Child Health \& Human Development of the National Institutes of Health under Award Number K12HD092535 and the funding support of all institutes: Office Of The Director, National Institutes of Health (OD) and National Institute of Dental \& Craniofacial Research (NIDCR).

\section{Compliance with Ethical Standards:}

Conflict of Interest: The authors declare that they do not have a conflict of interest.
Disclaimer: The content is solely the responsibility of the authors and does not necessarily represent the official views of the NIH

\section{REFERENCES}

1. Braveman P, Egerter S, Williams DR. The social determinants of health: coming of age. Annu Rev Public Health 2011;32:381-398.

2. Sameroff AJ, Rosenblum KL. Psychosocial constraints on the development of resilience. Ann N Y Acad Sci 2006;1094:116-124.

3. Committee on the Recommended Social and Behavioral Domains and Measures for Electronic Health Records, Board on Population Health and Public Health Practice, IOM. Capturing Social and Behavioral Domains and Measures in Electronic Health Records: Phase 2. http:// nationalacademies.org/hmd/Reports/2014/EHRdomains2.aspx.

4. Hosseinpoor AR, Stewart Williams $\mathbf{J}, \mathbf{A m i n} \mathbf{A}$, et al. Social determinants of self-reported health in women and men: understanding the role of gender in population health. PLoS One 2012;7(4):e34799.

5. Giuse NB, Koonce TY, Kusnoor SV, et al. Institute of Medicine Measures of Social and Behavioral Determinants of Health: a feasibility study. Am J Prev Med 2017;52(2):199-206.

6. Tobiasz-Adamczyk B, Galas A, Zawisza $\mathbf{K}$, et al. Gender-related differences in the multi-pathway effect of social determinants on quality of life in older age-the COURAGE in Europe project. Qual Life Res 2017;26(7):1865-1878.

Publisher's Note Springer Nature remains neutral with regard tojurisdictional claims in published maps and institutional affiliations. 